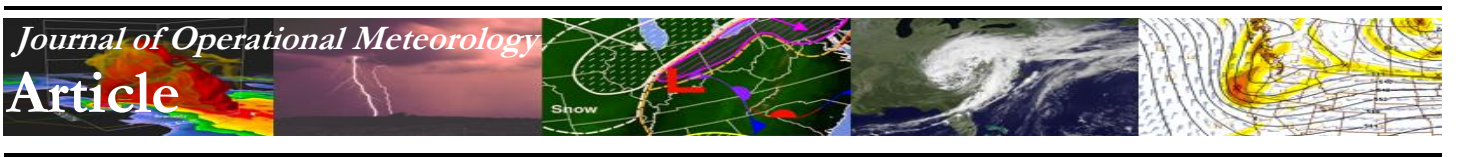

\title{
Evaluation of Near Real-Time Preliminary Tornado Damage Paths
}

\author{
CHRISTOPHER D. KARSTENS \\ Cooperative Institute for Mesoscale Meteorological Studies, University of Oklahoma, Norman, Oklahoma \\ NOAA/OAR/National Severe Storms Laboratory, Norman, Oklahoma \\ KACIE N. SHOURD \\ University of Nevada, Reno, Atmospheric Sciences Graduate Program, Reno, Nevada \\ DOUG SPEHEGER, AARON ANDERSON, RICHARD SMITH, and DAVID ANDRA \\ NOAA/NWS/Weather Forecast Office, Norman, Oklahoma \\ TRAVIS M. SMITH \\ Cooperative Institute for Mesoscale Meteorological Studies, University of Oklahoma, Norman, Oklahoma \\ NOAA/OAR/National Severe Storms Laboratory, Norman, Oklahoma \\ VALLIAPPA LAKSHMANAN \\ Google, Seattle, Washington \\ SOMER A. ERICKSON \\ DHS/FEMA, Washington, D.C. \\ NOAA/NWS/Storm Prediction Center, Norman, Oklahoma
}

(Manuscript received 2 November 2015; review completed 6 July 2016)

\begin{abstract}
The ability to preliminarily diagnose areas damaged by a tornado is examined using both a manual and an automated approach. The manual method consists of using Weather Surveillance Radar-1988 Doppler base data to track radar-indicated centroids of low-level rotation over the entirety of a tornado event. The automated method utilizes 0-2- and 3-6-km AGL azimuthal shear from the Multi-Radar Multi-Sensor system to link together a series of strong azimuthal shear clusters and create a proposed damage path polygon. The quality of each method's diagnosis is evaluated using traditional verification metrics derived from an object-based geospatial verification technique. These metrics indicate that the preliminary damage paths from the manual method better detect damaged areas with less false area denoted, compared to preliminary damage paths from the automated method. However, the preliminary damage paths from all methods fall short of detecting the entirety of damaged areas, and they also denote large areas in the damage path vicinity that were not affected. Potential avenues for future research and applications are described.
\end{abstract}

\section{Introduction}

In the wake of natural disasters (e.g., tornadoes, hurricanes, floods), areas directly impacted are not always immediately obvious or well known, nor is the magnitude of the damage readily apparent. Therefore, it is imperative that local first responders - as well as local, regional, and national emergency management officials - have access to the best possible information for determining the affected areas as quickly as possible so that resources can be allocated to these areas for timely and effective response. This issue is of particular importance for tornadoes that impact major metropolitan areas, where the potential for significant damage and loss of life is high. In many instances, National Weather Service (NWS) forecasters have a general idea of where the strongest low-level rotation occurred in a strong tornado event (based on interpretation of real-time radar data), but they lack a means of communicating their knowledge to those who need it. 
In 2008 the National Severe Storms Laboratory (NSSL) began providing radar-derived rotation tracks, utilizing the Multi-Radar Multi-Sensor (MRMS) system, to the NWS shortly after events via an on-demand web-interface (Fig. 1; Manross et al. 2008). This information is distributed as a Keyhole Markup Language (KML) image that can be overlaid in geographic information systems (GIS) or geospatial applications (e.g., Google Earth ${ }^{\mathrm{TM}}$ ). Rotation tracks are a time-accumulation of gridded azimuthal shear (Smith and Elmore 2004) over a layer (available layers include $0-2$ or 3-6 $\mathrm{km}$ AGL), thus giving an indication of where the strongest rotation occurred from either a single storm or several storms occurring in some region. Rotation tracks have a demonstrated value to the NWS for developing damage survey strategies, as well as to NWS partners [e.g., American Red Cross, Federal Emergency Management Agency (FEMA), local first responders, and emergency management] for positioning recovery assets. In recognition of these efforts, the development team was honored with a Technology Transfer award in 2013 (NSSL 2013).

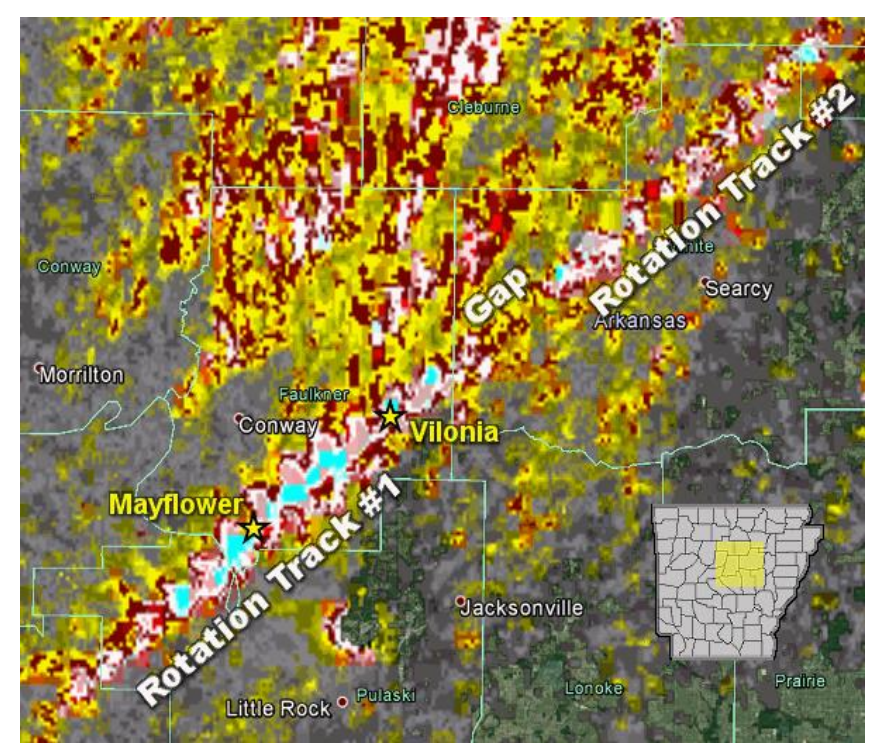

Figure 1. Example of NSSL rotation tracks for the MayflowerVilonia tornado event of 27 April 2014, overlaid in Google Earth ${ }^{\mathrm{TM}}$ (from www.srh.noaa.gov/lzk/?n=svr0414c.htm ). Click image for an external version; this applies to all figures hereafter.

More recently, the Norman Weather Forecast Office (WFO) developed a tool that allows a forecaster to produce a preliminary tornado damage path from radar data in a vector GIS format. In the moments during and immediately following the May 2013 central Oklahoma tornadoes, the Norman WFO produced preliminary tornado damage paths as shown in Fig. 2 (NWS
2014). According to the associated service assessment (NWS 2014), these preliminary damage paths were produced in KML format and subsequently distributed to (i) local first responders in the affected areas, (ii) FEMA, and, eventually (iii) the public in graphical form via social media (Fig. 2).

The GIS compatibility of these damage paths allowed FEMA to immediately display this critical information in their native software so that they could begin making decisions about the allocation and positioning of resources within and near the affected areas. This information exchange allowed resources to be deployed approximately 3-4 h prior to being requested by local emergency management; consequently, this resulted in quicker and more effective response by responders in the immediate wake of the event. The success of this multiagency effort led to the following service assessment recommendation (NWS 2014): "WFOs should be provided with the capability and procedures to create GIS products for possible tornado tracks in near real-time."

The tornado events of May 2013 and the efforts of the Norman WFO illustrate the potential benefits of near real-time preliminary tornado damage paths. In particular, these events demonstrate the added value of utilizing vector GIS datasets in decision-making. However, it is unclear how well these techniques will work in different circumstances. For example, can tornado damage paths be produced for weaker tornadoes and/or those at far-ranges from the source radar? What about short- versus long-duration events? Therefore, the primary purpose of this study is to analyze the performance of preliminary tornado damage paths for an expanded - though limited - set of tornado events. This analysis is accomplished by comparing the performance of forecaster-generated (manual) preliminary damage paths to automated preliminary damage paths. The automated preliminary damage paths are created by converting gridded rotation tracks to a vector GIS format-similar to the manually generated damage paths. Section 2 describes the methods developed to create the aforementioned preliminary tornado damage paths. The results of the evaluations are provided in section 3, with conclusions and recommendations given in section 4 .

\section{Methods}

\section{a. Manually and automatically estimated damage paths}

The method developed and used by the Norman WFO involves manually tracking radar-indicated cen- 


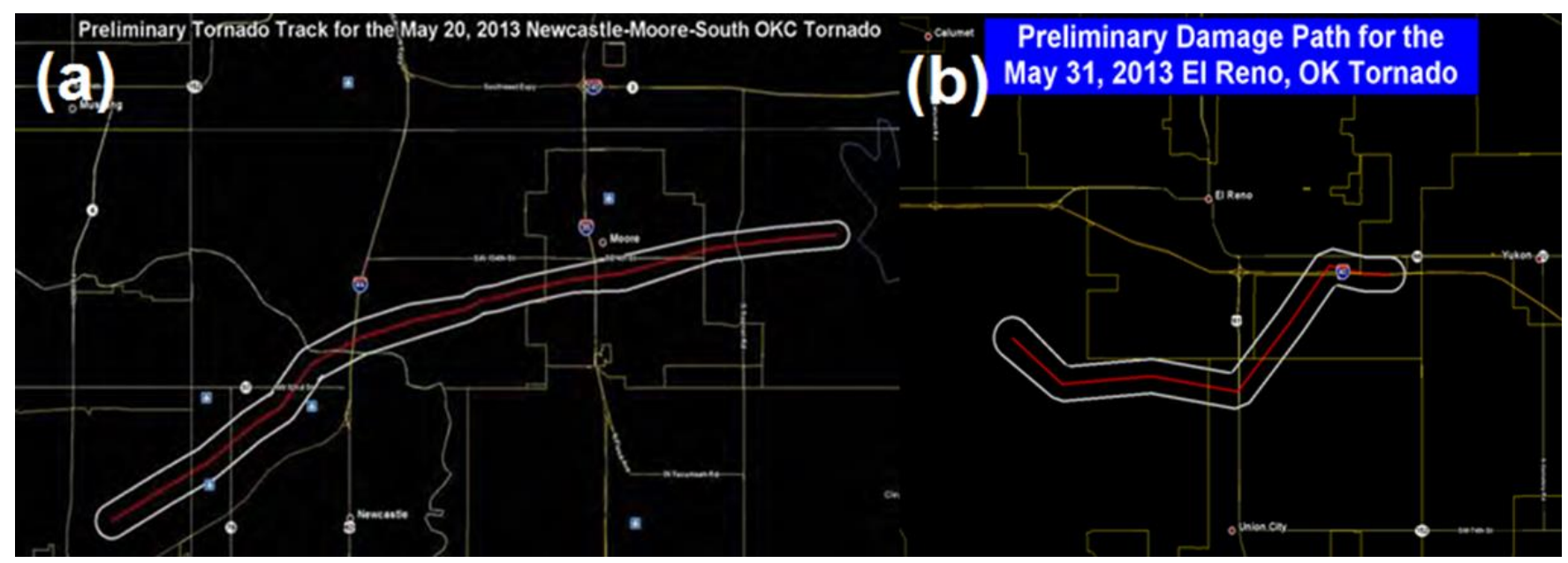

Figure 2. Preliminary tornado damage paths from (a) 20 May and (b) 31 May 2013 produced by WFO Norman in a GIS-compatible format.

Table 1. Distance criteria for determining which empirically derived equation to use for calculating the track line uncertainty distance. Each range-dependent buffer radius was determined using an $85 \%$ confidence of encompassing the center of the tornado path at each radar volume scan, based on 40 tornadoes from across the country occurring between 20 February 2009 and 13 April 2012.

\begin{tabular}{|l|l|}
\hline Distance Criteria & Buffer Radius Equation \\
\hline $0 \mathrm{~km}<d<64.4 \mathrm{~km}$ & buffer radius $=0.48 \mathrm{~km}+d \times 0.005$ \\
$(0 \mathrm{mi}<d<40 \mathrm{mi})$ & (buffer radius $=0.3 \mathrm{mi}+d \times 0.005)$ \\
\hline $64.4 \mathrm{~km} \leq d<128.7 \mathrm{~km}$ & buffer radius $=0.16 \mathrm{~km}+d \times 0.01$ \\
$(40 \mathrm{mi} \leq d<80 \mathrm{mi})$ & (buffer radius $=0.1 \mathrm{mi}+d \times 0.01$ ) \\
\hline $128.7 \mathrm{~km} \leq d$ & buffer radius $=d \times 0.015-0.48 \mathrm{~km}$ \\
$(80 \mathrm{mi} \leq d)$ & (buffer radius $=d \times 0.015-0.3 \mathrm{mi}$ ) \\
\hline
\end{tabular}

troids of low-level rotation over the entirety of a tornado event. Locations of low-level rotation (typically determined using base velocity) were manually cross-referenced with other radar moments, such as reflectivity and correlation coefficient. These centroids were then combined to form a track line (red lines in Fig. 2). However, Speheger and Smith (2006) showed that displacement errors of up to $12.87 \mathrm{~km}(8 \mathrm{mi})$ can occur between the radar-derived circulation centers and the observed tornado tracks. Therefore, this track line is an approximation. Further, the Speheger and Smith study showed that these displacement errors increase with increasing distance from the radar source. Therefore, to account for these elements of uncertainty, a buffer (i.e., circle) with a range-dependent radius (Table 1) was computed around each low-level rotation centroid, and these buffers were connected to form a polygon around the track line (white lines in Fig. 2). Thus, the buffered regions represent uncertainty in the position of the track line and are not a direct indication of an approximated tornado damage path (i.e., area). However, for the purposes of this study, the level of correspondence of these buffered regions to observed damage paths was explored, so this limitation should be kept in mind when interpreting the results. This method was performed for observed damage paths within at least a \pm 30 -min window of the tornado event, and was conducted by a single forecaster from WFO Norman for all of the manually produced damage paths analyzed in this study.

The process of automatically creating an estimated tornado damage path from MRMS azimuthal shear (Fig. 3a) is a multi-step process, similar to the method documented in Miller et al. (2013). First, an 11-point (approximately $5.5-\mathrm{km}$ radius) Gaussian filter was used to smooth the gridded 0-2- and 3-6-km AGL azimuthal shear (Fig. 3b; Lakshmanan et al. 2006). Using this smoothed field, the advanced watershed method (Lakshmanan et al. 2009) was used to grow and identify objects that had $\geq 30$ grid points exceeding a threshold value of $0.010 \mathrm{~s}^{-1}$. Objects of this horizontal length reside within the meso-gamma scale of motion and are associated with radar-identified mesocyclones. Identified objects were then tracked over time using a search radius of three times the size or within $15 \mathrm{~km}$ of the object (Lakshmanan and Smith 2010). Once an identified object was not found within this search window in successive fields, the object history was assumed to end and the tracked objects were combined (identical to the WFO method of creating a polygon) and written to a polygon shapefile (Fig. 3c). This method was performed for preliminary damage paths within at least a \pm 30 -min window of the tornado event. Note that preliminary damage paths associated with 

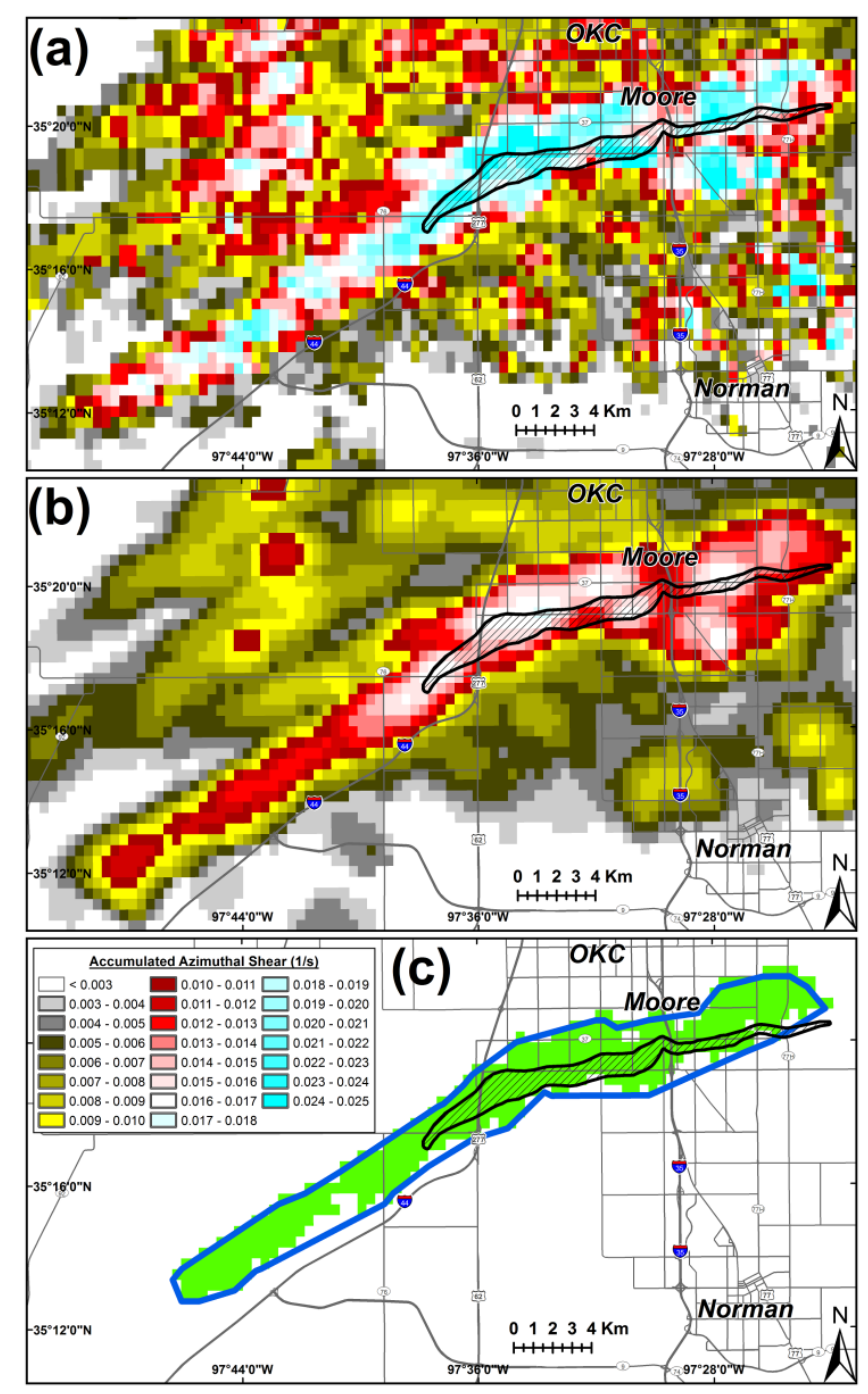

Figure 3. Visual overview demonstrating how the automated preliminary damage paths were generated. (a) The azimuthal shear (e.g., 3-6 km AGL) field was acquired within a \pm 30 -min window of the tornado event; (b) the raw azimuthal shear field was smoothed at each time step; and (c) identified objects exceeding the threshold criteria were tracked over time until the threshold was not met, thus creating the preliminary damage path (blue contour). The black hatched area indicates the observed damage path.

other storms were often identified; however, these preliminary damage paths were ignored for the purposes of this study. Additionally, the exact object identification and tracking settings were chosen through an iterative empirical analysis. It would be advantageous in the future to repeat this analysis more thoroughly within an appropriate spectrum of settings.

\section{b. Verification}

In addition to the two events for which near realtime tornado damage paths were generated by WFO
Norman, eight additional tornado events were analyzed in this study, for a total of 10 events. A summary of the details for each tornado event is provided in Table 2. Note, events $9 \mathrm{a}$ and $9 \mathrm{~b}$ in Table 2 consist of two simultaneous tornado events that were combined when assessing the performance of the preliminary tornado damage paths. The expanded dataset includes tornado events rated in the mid- to upper-range of the EF-scale (EF-3+) - emphasizing events with confirmed higher-end damage - for a variety of locations, path lengths, path widths, and distances from the radar. In addition, each tornado event was chosen based on the availability of a digitized damage path in the NWS Damage Assessment Toolkit (Camp et al. 2014). For these events, the EF-0 polygon contour (maximum extent of tornado damage) was used as the observed tornado damage path for each case. Note that a sample size of 10 is still quite small (a consequence of limited data availability), and this limitation should be kept in mind when interpreting the results of this study.

To assess the quality of each method's diagnosis of the preliminary tornado damage path, an objectbased geospatial verification technique was developed. First, in each case a geospatial intersection was performed between the preliminary tornado damage path and the observed tornado damage path. The result of this intersection yielded, at most, three classes of polygons that could be categorized using the traditional contingency table method and performance metrics (Wilks 2006; Table 3). The performance metrics of relevance for this study include probability of detection (POD), false alarm ratio (FAR), success rate (SR), critical success index (CSI), and bias, defined as,

$$
\begin{aligned}
& \mathrm{POD}=\frac{A}{A+C}, \\
& \mathrm{FAR}=\frac{B}{A+B}, \\
& \mathrm{SR}=1-\mathrm{FAR}, \\
& \mathrm{CSI}=\frac{A}{A+B+C}, \text { and } \\
& \text { bias }=\frac{A+B}{A+C},
\end{aligned}
$$

where $\mathrm{A}, \mathrm{B}$, and $\mathrm{C}$ are defined in Table 3. An example of this classification method is provided in Fig. 4. Hits (A) are polygons labeled as areas where the prelimnary and observed damage path overlapped, false de- 
Table 2. Tornado events used for verifying the preliminary tornado damage paths.

\begin{tabular}{|c|c|c|c|c|c|c|c|c|}
\hline $\begin{array}{c}\text { Event } \\
\text { Number }\end{array}$ & $\begin{array}{l}\text { Start Time } \\
\text { (UTC) }\end{array}$ & $\begin{array}{l}\text { End Time } \\
\text { (UTC) }\end{array}$ & $\begin{array}{c}\text { EF-Scale } \\
\text { Rating }\end{array}$ & $\begin{array}{l}\text { Path Length } \\
\text { (km; mi) }\end{array}$ & $\begin{array}{l}\text { Max Width } \\
\text { (km; yards) }\end{array}$ & $\begin{array}{l}\text { Source } \\
\text { Radar }\end{array}$ & $\begin{array}{l}\text { Closest Distance } \\
\text { from Radar (km) }\end{array}$ & $\begin{array}{l}\text { Longest Distance } \\
\text { from Radar }(\mathbf{k m})\end{array}$ \\
\hline 1 & $5 / 15 / 13,2258$ & $5 / 15 / 13,2311$ & EF-4 & $4.02 ; 2.5$ & $0.37 ; 400$ & KFWS & 42.7 & 46.5 \\
\hline 2 & $5 / 16 / 13,0212$ & $5 / 16 / 13,0223$ & EF-3 & $12.54 ; 7.79$ & $1.58 ; 1733$ & KFWS & 28.0 & 40.0 \\
\hline 3 & $5 / 20 / 13,1856$ & $5 / 20 / 13,1935$ & EF-5 & $22.29 ; 13.85$ & $1.74 ; 1900$ & KTLX & 11.3 & 32.9 \\
\hline 4 & $5 / 31 / 13,2303$ & $5 / 31 / 13,2344$ & EF-3 & $26.07 ; 16.2$ & $4.18 ; 4576$ & KTLX & 55.6 & 77.4 \\
\hline 5 & $6 / 1 / 13,0050$ & 6/1/13, 0108 & EF-3 & $51.03 ; 31.71$ & $1.61 ; 1760$ & KLSX & 1.0 & 25.1 \\
\hline 6 & $11 / 17 / 13,1659$ & $11 / 17 / 13,1747$ & EF-4 & $74.61 ; 46.36$ & $0.8 ; 880$ & KILX & 54.3 & 54.7 \\
\hline 7 & 4/28/14, 0006 & 4/28/14, 0059 & EF-4 & $66.14 ; 41.1$ & $1.21 ; 1320$ & KGWX & 18.5 & 37.8 \\
\hline 8 & 4/29/14, 0109 & $4 / 29 / 14,0127$ & EF-3 & $43.07 ; 26.76$ & $0.46 ; 500$ & KHTX & 35.4 & 43.3 \\
\hline $9 a$ & $6 / 16 / 14,2100$ & $6 / 16 / 14,2146$ & EF-4 & $38.53 ; 23.94$ & $0.46 ; 500$ & KOAX & 94.9 & 97.6 \\
\hline $9 b$ & $6 / 16 / 14,2113$ & 6/16/14, 2139 & EF-4 & $18.51 ; 11.5$ & $0.46 ; 500$ & KOAX & 91.6 & 100.6 \\
\hline 10 & $6 / 16 / 14,2140$ & $6 / 16 / 14,2208$ & EF-4 & $25.49 ; 15.84$ & $0.48 ; 530$ & KOAX & 97.9 & 121.2 \\
\hline
\end{tabular}

Table 3. The $2 \times 2$ contingency table.

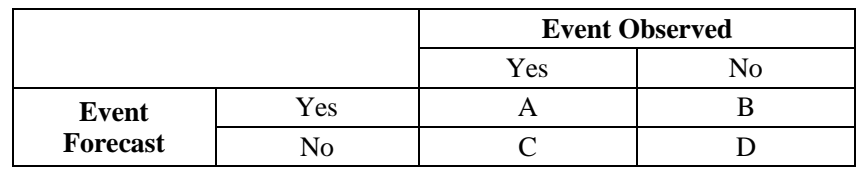

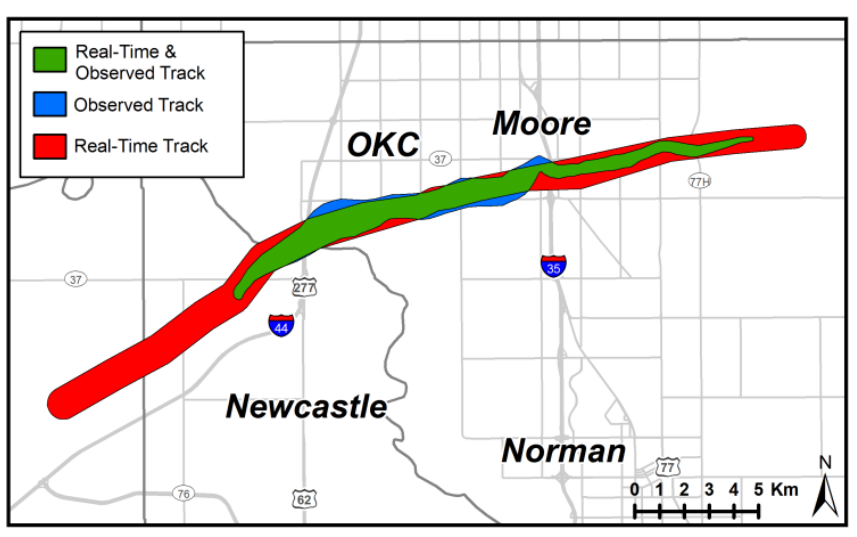

Figure 4. Example of the object-based geospatial verification technique developed to evaluate the quality of the proposed damage paths of this study. Green areas correspond to hits, blue areas are misses, and red areas are false detections. An electronic supplement for analyzing the classification method of geospatial verification for each damage path is available at hwt.nssl.noaa.gov/ damagepaths/verification.php.

tections (B) are areas where a preliminary damage path did not overlap with observed damage, and misses (C) are areas where observed damage occurred with no preliminary damage path. For each tornado event, the area(s) for each polygon classification were summed and normalized by the total area of the observed damage path polygon. Thus, if a preliminary damage path perfectly matched the observed damage area, the preliminary damage polygon received perfect performance metrics (i.e., $\mathrm{POD}=1, \mathrm{FAR}=0, \mathrm{SR}=1$, $\mathrm{CSI}=1$, and bias $=1$ ). These performance metrics are visualized and evaluated using a performance diagram (Roebber 2009).

\section{Results}

A summary of the performance metrics comparing the automated and manual damage paths for each tornado event is provided in Figs. 5 and 6 using 0-2- and 3-6-km AGL azimuthal shear, respectively. In addition, an electronic supplement for analyzing the classification method of geospatial verification for each damage path - using the coloring/labeling scheme in Fig. 4, in conjunction with Figs. 5 and 6 -is available at hwt.nssl.noaa.gov/damagepaths/verification.php. In general, the automated damage paths tend to have less skill in correctly diagnosing areas where observed damage occurs, as denoted by a mean POD of approximately $0.49(0-2 \mathrm{~km})$ and $0.44(3-6 \mathrm{~km})$, compared to the damage paths of the manual method, with a POD of approximately 0.74 . Additionally, the damage paths of automated methods tend to falsely diagnose areas where observed damage did not occur, as denoted by a mean SR of approximately $0.23(0-2 \mathrm{~km})$ and 0.16 (3-6 km), compared to the manual method, with an SR 


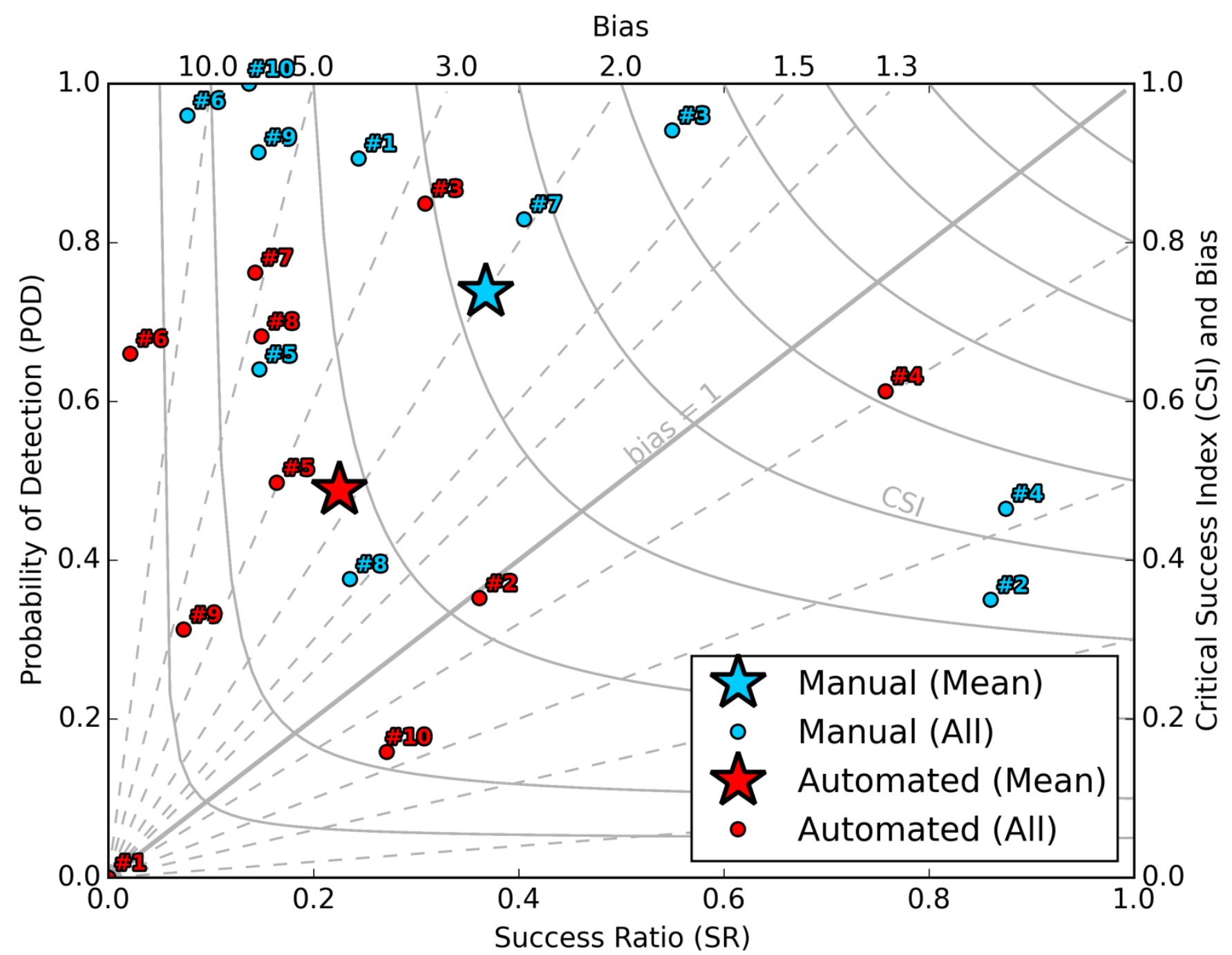

Figure 5. Performance diagram for evaluating the quality of the preliminary damage paths from the manual and automated methods (using 0-2-km AGL azimuthal shear). Each point label corresponds to the event number provided Table 2. Note that label \#9 represents the combination of $9 \mathrm{a}$ and $9 \mathrm{~b}$ from Table 2 .

of approximately 0.37 . Consequently, the automated damage paths tend to have a lower CSI, near 0.18 (0-2 $\mathrm{km})$ and $0.13(3-6 \mathrm{~km})$, and a higher bias, near 2.2 $(0-2 \mathrm{~km})$ and $2.9(3-6 \mathrm{~km})$, compared to the damage paths of the manual method (near 0.32 and 2.0, respectively). This comparison also reveals that the performance of the automated damage paths derived using the $0-2-\mathrm{km}$ AGL azimuthal shear is better than those derived using the 3-6-km AGL layer.

In addition to the mean performance statistics, the performance of each proposed damage path from each method is shown in Figs. 5 and 6. Damage paths from the automated method using the $0-2-\mathrm{km}$ azimuthal shear layer in Fig. 5 show 9 of the 10 events with SR $<0.4$, CSI $<0.3$, bias $>2.5$, and widely varying POD. One outlier is event 4 , the largest tornado event that occurred mid-range to the radar, having exceptionally good performance, with a POD just above 0.6 , SR near 0.75 , CSI just above 0.5, and bias near 0.8. Another notable outlier is event 1 , the smallest tornado event occurring close to the radar, where this method was unable to identify a proposed damage path using the 0-2-km AGL azimuthal shear overlapping the observed damage path. Geospatially, many of these proposed damage paths appear to align well with the axis of the observed damage path, but are commonly out of synchronization with the observed path length (i.e., the automated method begins identifying objects before/ after observed damage has occurred and/or observed damage ends before/after the object identification has ended). 


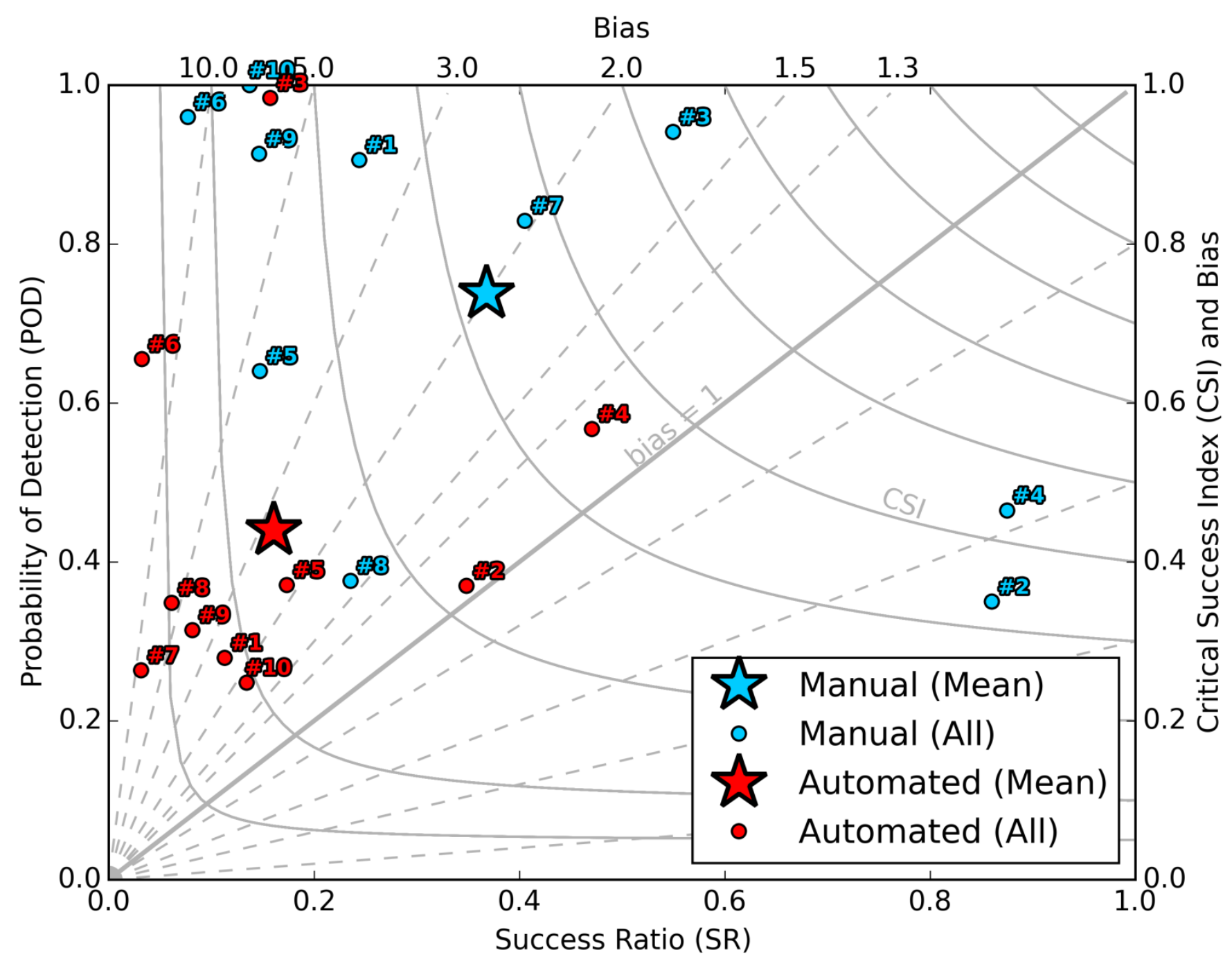

Figure 6. As in Fig. 5 except using 3-6-km AGL azimuthal shear with the automated method.

The damage paths from the automated method using the 3-6-km azimuthal shear layer in Fig. 6 show a clustering of points in the bottom-left of the figure, indicative of low POD (0.2-0.4), low SR (0-0.2), low CSI (0.05-0.15), and high bias (1.5-10). Interestingly, two outliers from the damage paths of the automated method cluster, events 3 and 6, had better POD (0.650.98 ) but with higher bias $(7+)$, indicating that these preliminary damage paths were able to capture more of the observed damage areas at the expense of encompassing larger areas that were not damaged. Two other outliers, events 2 and 4, had marginally better performance metrics (POD of 0.4-0.6 and SR of 0.350.5 ) and a bias near 1 , indicating that these preliminary tracks were comparable in size to the observed damage paths, but slightly offset from one another.

The damage paths of the manual method show some indication of points clustered in the upper-left corner of Figs. 5 and 6, indicative of high POD (0.9+), low SR $(<0.3)$, low CSI $(<0.3)$ and high bias $(>4.5)$. Thus, these preliminary damage paths are able to diagnose the damaged areas well, but at the expense of encompassing large areas that were not damaged. Two notable outliers are located on the right side of Fig. 5, with moderate POD (0.35-0.5) and high SR (>0.8), leading to low bias $(0.35-0.5)$. The low bias indicates that these preliminary damage paths were considerably smaller than the observed damage path. This result is perhaps not surprising, given that the manual method is intended to denote uncertainty about the central axis of the tornado track, as opposed to a damage path polygon, as noted previously.

Finally, the display of the individual cases in Figs. 5 and 6 allows for a performance comparison of the three methods of preliminary damage path creation relative to each other. Using CSI as the comparative 
metric, the manual method performed better in 7 out of the 10 cases compared to the automated method using $0-2-\mathrm{km}$ azimuthal shear, and in 9 out of the 10 cases compared to the automated method using 3-6-km azimuthal shear. Only one case showed improved performance using an automated method (\#4 using 0-2 azimuthal shear), and the rest showed approximately similar performance. Further, the automated method using $0-2 \mathrm{~km}$ azimuthal shear performed better in 5 cases, similarly in 4 cases, and worse in the remaining case (\#1 where no damage path was produced using the $0-2-\mathrm{km}$ azimuthal shear) compared to the automated method using 3-6-km azimuthal shear.

\section{Conclusions and recommendations}

In this study, the ability to preliminarily diagnose areas damaged by a tornado was examined using one manual and two automated approaches. The manual method consists of using Weather Surveillance Radar1988 Doppler base data to track radar-indicated centroids of low-level rotation over the entirety of a tornado event. The automated methods utilize 0-2and 3-6-km AGL azimuthal shear from the MRMS system to link together a series of strong azimuthal shear clusters and create a proposed damage path polygon. The quality of each method's diagnosis was evaluated using traditional verification metrics derived from an object-based geospatial verification technique.

The verification results indicate, in general, that the damage paths of the manual method do a better job of detecting areas with tornado damage, along with indicating marginally less false area, compared to the damage paths of the automated methods. All methods have a high bias, indicating that the preliminary damage paths denote an area much larger than the observed damage path. The high biases are attributable to uncertainty of the exact areas with tornado damage, as the methods utilize remotely sensed data to derive a preliminary damage path. Because the exact tornado damage path cannot be known with a higher level of certainty until a damage survey is conducted, denoting large areas in the vicinity of the observed damage path seems reasonable until refinements can be made. This tradeoff is relevant when comparing the performance of the manual (available within approximately $1 \mathrm{~h}$ after the event) and automated methods (available within a few minutes after the event). With these results it is important to be mindful of the small sample of events used in this study.
When evaluating the performance for the prelimnary damage paths individually, the damage paths of the manual method had the best overall performance, followed by the automated methods using 0-2- and 3-6-km azimuthal shear, respectively. Additionally, the metrics from damage paths using the manual method show greater variability compared to the automated method using 3-6-km AGL azimuthal shear, but similar to those using azimuthal shear for the $0-2-\mathrm{km}$ layer. The larger variance of the manually derived damage paths likely is attributable to the narrowness of these paths, given that this method is intended to denote uncertainty about the central axis of the tornado track (line) as opposed to a damage path (area). Many of the automated damage paths using the $0-2-\mathrm{km}$ azimuthal shear appear to align well with the axis of observed damage paths, but the object identification appears out of synchronization with the observed damage path length. The degraded performance of the $3-6-\mathrm{km}$ automatically derived damage paths appears to be, in some cases, attributable to an offset in the axis of the damage path polygon, as compared to the observed damage path. This spatial offset likely is attributable to using midlevel rotation for identifying surface damage, as the two are not always well correlated, especially during the later stages of a tornado.

There are many avenues of potential future research topics to explore here. To start, it could be advantageous to systematically perform a spatial bias correction of the preliminary damage path polygons and reexamine the performance with a different set of observed tornado damage paths to identify any potential improvements. For the automated method, it would be interesting to perform a sensitivity analysis with customized layers of azimuthal shear. It is hypothesized that increasing the depth of the layer (e.g., 1-5 $\mathrm{km}$ AGL), thus capturing broader aspects of rotation, would improve this method's performance metrics. Alternative data types could be explored, such as algorithms for detecting the tornado debris signature (Smith et al. 2014; Snyder and Ryzhkov 2015), in addition to adjustments in object identification settings for the automated method. Adding a width attribute to each low-level rotation centroid for the manual method could help improve spatial detection for large circulations producing large tornadoes (case \#4).

An additional avenue of future development to explore is the specific needs of various government agencies to enhance decision making in the critical moments following a tornado event. For example, 

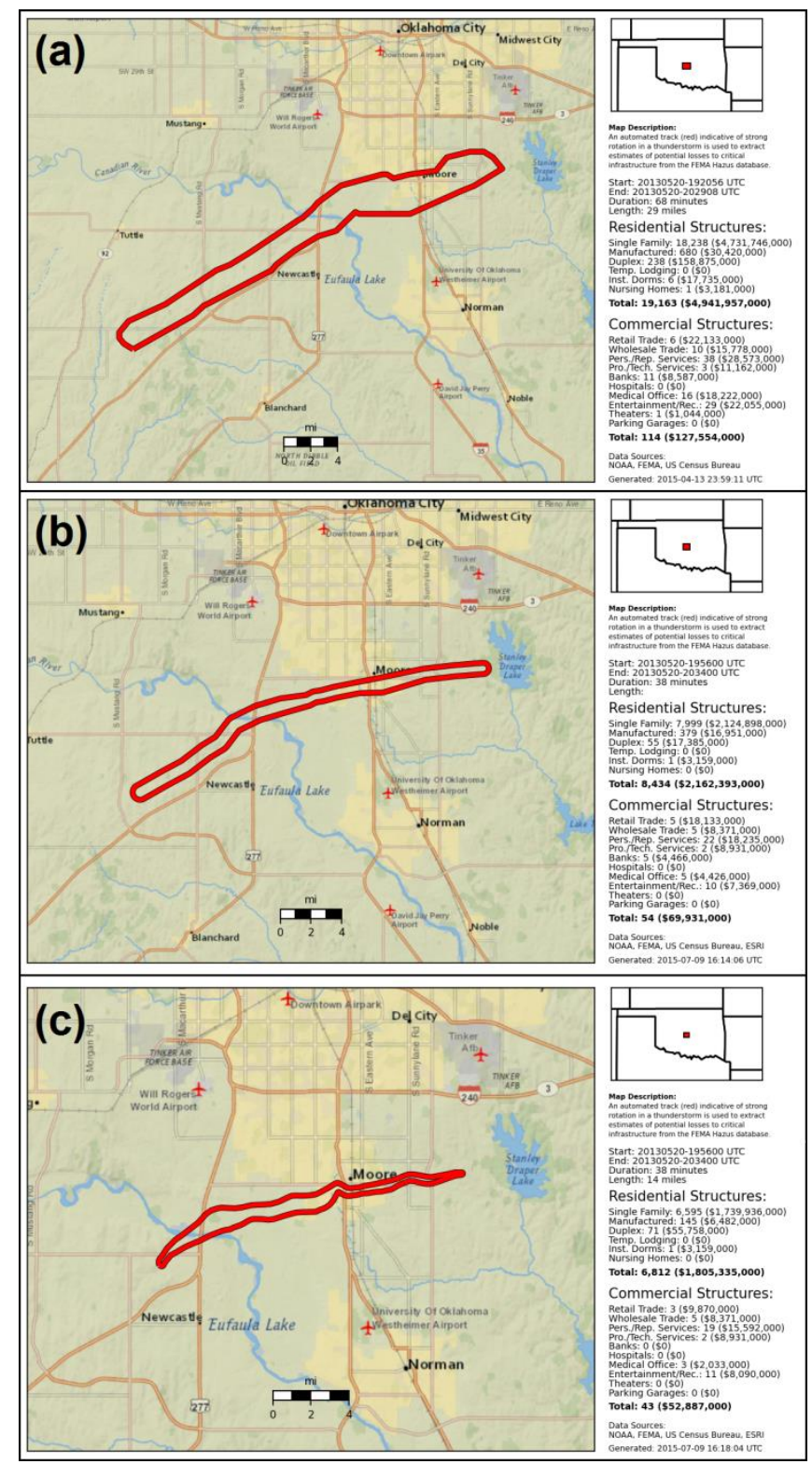

Figure 7. Maps with estimates (counts and monetary value) of critical infrastructure encompassed by a) an automated, radarderived rotation track, b) a human forecaster estimated damage path, and c) the final observed damage path (EF-0 contour).

emergency management agencies at the local and state level - and eventually FEMA - ultimately need to know the magnitude of damage (i.e., quantity, type, and monetary value of infrastructure) in the affected areas to help determine their level of response. Thus, extracting such information from within a preliminary damage path polygon and providing a summary of infrastructure attributes, automatically, would be advantageous. An example of this summary information using the FEMA Hazards United States database, for three tornado damage paths (automated method using 3-6-km azimuthal shear, manual method, and observations), is provided in Fig. 7.

The methods of this study are currently in the process of being transitioned to NWS operations (Scheck et al. 2016). However, the findings of this study emphasize that the "preliminary" aspect of these tornado damage path polygons should be kept in mind when distributing such information within the NWS and to its partners. The preliminary aspect of this information becomes more apparent when examining how such information could be used for decision making, as shown in Fig. 7. The methods analyzed herein are not perfect, and all methods tend to map out areas much larger than the observed damage paths. Nevertheless, there is a clear need for such information in the immediate wake of a tornado event.

Acknowledgments. This paper was prepared with funding provided by the United States Weather Research Program's Hazardous Weather Testbed Research Opportunity, NOAA/Office of Education Hollings Scholarship Program, and NOAA/Office of Oceanic and Atmospheric Research under NOAA-University of Oklahoma Cooperative Agreement \#NA11OAR4320072, United States Department of Commerce. The authors thank Darrel Kingfield, Patrick Marsh, James Correia Jr., Greg Carbin, and two anonymous reviewers for their constructive comments and suggestions. The statements, findings, conclusions, and recommendations are those of the authors and do not necessarily reflect the views of NOAA or the United States Department of Commerce.

\section{REFERENCES}

Camp, J. P., L. P. Rothfusz, A. Anderson, D. Speheger, K. L. Ortega, and B. R. Smith, 2014: Assessing the Moore, Oklahoma (2013) tornado using the National Weather Service Damage Assessment Toolkit. Preprints, Special Symposium on Severe Local Storms: The Current State of the Science and Understanding Impacts, Atlanta, GA, Amer. Meteor. Soc., 830. [Available online at ams.confex.com/ams/94Annual/webprogram/Paper233 734.html.]

Lakshmanan, V., and T. M. Smith, 2010: An objective method of evaluating and devising storm-tracking algorithms. Wea. Forecasting, 25, 701-709, Crossref. , T. Smith, K. Hondl, G. J. Stumpf, and A. Witt, 2006: A real-time, three-dimensional, rapidly updating, heterogeneous radar merger technique for reflectivity, velocity, and derived products. Wea. Forecasting, 21, 802-823, Crossref.

, K. Hondl, and R. Rabin, 2009: An efficient, generalpurpose technique for identifying storm cells in geo- 
spatial images. J. Atmos. Oceanic Technol., 26, 523537, Crossref.

Manross, K. L., T. M. Smith, J. T. Ferree, and G. J. Stumpf, 2008: An on-demand user interface for requesting multi-radar, multi-sensor time accumulated products to support severe weather verification. Preprints, 24th Conf. on Interactive Information Processing Systems, New Orleans, LA, Amer. Meteor. Soc., P2.13. [Available online at ams.confex.com/ams/pdfpapers/ 134621.pdf.]

Miller, M. L., V. Lakshmanan, and T. M. Smith, 2013: An automated method for depicting mesocyclone paths and intensities. Wea. Forecasting, 28, 570-585, Crossref.

NSSL, cited 2013: NSSL/CIMMS team receives 2013 NOAA Technology Transfer Award. [Available online at www.nssl.noaa.gov/briefings/2013/09/nsslcimmsteam-receives-2013-noaa-technology-transfer-award/.]

NWS, cited 2014: Service assessment: May 2013 Oklahoma tornadoes and flash flooding. [Available online at www.nws.noaa.gov/os/assessments/pdfs/13oklahoma $t$ ornadoes.pdf.]

Roebber, P. J., 2009: Visualizing multiple measures of forecast quality. Wea. Forecasting, 24, 601-608, Crossref.

Scheck, J. W., and Coauthors, 2016: Embracing the new NWS financial and organizational structure: Leading a multi-office damage path tool project to support a FEMA-requested service. Preprints, Fourth Symposium on Building a Weather-Ready Nation: Enhancing our Nation's Readiness, Responsiveness, and Resilience to
High-Impact Weather, New Orleans, LA, Amer. Meteor. Soc., 10.6. [Available online at ams.confex.com/ ams/96Annual/webprogram/Paper287788.html.]

Smith, T. M., and K. L. Elmore, 2004: The use of radial velocity derivative to diagnose rotation and divergence. Preprints, 11th Conf. on Aviation, Range, and Aerospace, Hyannis, MA, Amer. Meteor. Soc., P5.6. [Available online at ams.confex.com/ams/pdfpapers/ 81827.pdf.]

D. M. Kingfield, and K. L. Ortega, 2014: Automated detection of tornado debris signature paths. Preprints, Special Symposium on Severe Local Storms: The Current State of the Science and Understanding Impacts, Atlanta, GA, Amer. Meteor. Soc., 836. [Available online at ams.confex.com/ams/94Annual/webprogram/ Handout/Paper241467/Kingfieldetal-2014-AutoTDSPoster.pdf.]

Snyder, J. C., and A. V. Ryzhkov, 2015: Automated detection of polarimetric tornado debris signatures using a hydrometeor classification algorithm. J. Appl. Meteor. Climatol., 54, 1861-1870, Crossref.

Speheger, D. A., and R. D. Smith, 2006: On the imprecision of radar signature locations and storm path forecasts. Natl. Wea. Dig., 30, 3-10. [Available online at www.nwas.org/digest/papers/2006/Vol30No1/Pg3Speheger.pdf.]

Wilks, D. S., 2006: Statistical Methods in the Atmospheric Sciences. 2nd ed. Academic Press, 648 pp. 